\title{
Caderno Educação em Direitos Humanos e governança: algumas similitudes com documentos da UNESCO e do Programa das Nações Unidas para o Desenvolvimento'
}

\author{
Maria José De Rezende² \\ ORCID: 0000-0002-3426-910X
}

\section{Resumo}

O Caderno Educação em Direitos Humanos (CEDH) indica que confia nos processos de governança para solucionar uma parte expressiva dos problemas educacionais. Essa convicção é muito semelhante à que tem sido externada também por diversos organismos internacionais, lideranças políticas, governantes e organizações da sociedade civil. A esses agentes caberia a tarefa de compor uma rede de ações e de procedimentos para expandir uma forma de educação capaz de transformar as pessoas em sujeitos de direitos e em indivíduos dotados da capacidade de impulsionar mudanças expressivas em sua vida e na vida dos demais indivíduos que vivem ao seu redor. Por meio de uma pesquisa documental histórico-hermenêutica concluiu-se que as prescrições, postas no CEDH, para trabalhar os princípios que orientam as Diretrizes Nacionais da Educação em Direitos Humanos, têm similaridades com as sugestões de geração de políticas de enlaçamento de diversos agentes, postas nos Relatórios do Desenvolvimento Humano do PNUD e nos Relatórios de Monitoramento Global das Metas de Educação para Todos, da UNESCO.

\section{Palavras-chave}

Educação - Direitos humanos - Governança - Desenvolvimento humano.

1- Parte deste texto foi apresentada oralmente no GT 22 e consta nos anais do VIII Congresso da ABraSD, ocorrido em Porto Alegre, entre 08 e 10 de novembro de 2017.

2- Universidade Estadual de Londrina (UEL); Londrina, Paraná. Brasil. Contato: mjderezende@gmail.com. 


\title{
The Human Rights Education Notebook and governance: some similarities with documents from UNESCO and the United Nations Development Program
}

\begin{abstract}
The Human Rights Education Handbook (HREH) indicates that one trusts in the ability of governance processes for solving a significant part of educational problems. This belief is very similar to that which has also been expressed by several international organizations, political leaders, government officials and civil society organizations. These agents would have the task of establishing a network of actions and procedures to expand a form of education capable of transforming people into subjects who have rights and individuals with the ability to trigger significant changes in their lives and in the lives of other individuals who live around them. Through historical-hermeneutic documentary research it was concluded that the prescriptions indicated in the HREH regarding the instructions issued by the National Guidelines of the Education in Human Rights have similarities with the suggestions of generation of politics of connection put forward by various agents, and included in the UNDP Human Development Reports and the UNESCO Education for All (EFA) Global Monitoring Reports.
\end{abstract}

\section{Keywords}

Education - Human rights - Governance - Human development.

\section{Introdução}

Investiga-se, neste artigo, um traço particular do Caderno Educação em Direitos Humanos (CEDH), ou seja, o que esboça as linhas de ações para que a Educação em Direitos Humanos (EDH) seja viabilizada por meio do "envolvimento da comunidade escolar, da rede de promoção e defesa dos direitos humanos, bem como dos gestores educacionais e sociais" (BRASIL; CEDH, 2013, p. 12).

Ainda que o Caderno Educação em Direitos Humanos (CEDH) não utilize a palavra governança para designar esse processo de envolvimento de uma multiplicidade de agentes na geração, desenvolvimento, gestão e efetivação de guias de ação, no campo da $\mathrm{EDH}$, ao ler-se o documento, veem-se as muitas linhas de ações que estão relacionadas a algumas noções de governança, veiculadas por organismos internacionais, como o PNUD (Programa das Nações Unidas para o Desenvolvimento), por meio dos RDHs (Relatórios do Desenvolvimento Humano) e a UNESCO (Organização das Nações Unidas para a Educação, 
a Ciência e a Cultura), por meio dos REPTs (Relatórios de Monitoramento Global das Metas Educação para Todos), que têm tomado corpo nas primeiras décadas do século XXI ${ }^{3}$.

O Caderno Educação em Direitos Humanos (CEDH) foi divulgado em 2013, pelo governo brasileiro, através da Secretaria Nacional de Promoção e Defesa dos Direitos Humanos (BRASIL; CEDH, 2013). Esse material sistematiza um conjunto de reflexões sobre os princípios básicos que orientam as Diretrizes Nacionais da Educação em Direitos (DNEDHs) e seus pareceres e resoluções $(2012 ; 2012 b)$. Além de trazer os princípios orientadores das diretrizes, o Caderno objetiva também expor diversas propostas metodológicas para auxiliar na viabilização das prescrições que estavam, desde 2006, no Plano Nacional da Educação em Direitos Humanos, para a área educacional. Ressalte-se que as diretrizes de 2012 devem ser vistas como resultado de um longo processo de debates, propostas e discussões acerca da educação no Brasil. Tomando-se a Carta Constitucional de 1988 como ponto nodal de uma tentativa de garantir que o país aja no campo dos direitos humanos, em consonância com o que vem sendo acordado nos muitos Atos Internacionais, vê-se que, desde então, há uma legislação interna e uma legislação infraconstitucional ${ }^{4}$ que passam a ordenar inúmeras ações no campo da efetivação dos direitos.

Por essa razão, nas décadas de 1990 e 2000 há alguns marcos fundamentais para que se fixem, em 2012, as Diretrizes Nacionais da Educação em Direitos Humanos (DNEDHs). Entre eles, podem ser mencionados os seguintes: a Lei de Diretrizes e Bases da Educação Nacional (LDBEN), o Programa Mundial de Educação em Direitos Humanos (PMEDH), o Plano Nacional de Educação em Direitos Humanos (PNEDH), Programa Nacional de Direitos Humanos - 3 (PNDH-3) (BRASIL; CEDH, 2013, p. 12), as Diretrizes Gerais para a Educação Básica, as Diretrizes Curriculares Nacionais para a Educação Infantil e as Diretrizes Curriculares do Ensino Fundamental de nove anos e para o Ensino Médio.

O Caderno Educação em Direitos Humanos (CEDH) informa que as diretrizes, de 2012, derivam de vários outros procedimentos que estiveram em curso desde o início da década de 2000, tais como a formação do Comitê Nacional de Educação em Direitos Humanos e sua formulação, "em 2003, em resposta a uma exigência da ONU referente à Década das Nações Unidas para a Educação em Direitos Humanos (1995-2004)” (BRASIL; CEDH, 2013, p. 11) e do Plano Nacional de Educação em Direitos Humanos. Tanto as diretrizes quanto o Caderno que as discutem são, assim, fruto de um conjunto de ações e ocorrências no plano interno e no externo ao país.

As propostas de Educação em Direitos Humanos, contidas nos documentos governamentais, poderiam ser estudadas sob vários aspectos, dentre os quais é possível investigar a concepção de direitos humanos, presente nas guias de ações indicadas nos Caderno de Educação em Direitos Humanos (CEDH), as orientações concernentes à proposta metodológica para trabalhar a Educação em Direitos Humanos (EDH), as instruções para a aplicação dos conteúdos das EDHs nas atividades escolares, os "discursos sobre os princípios norteadores da EDH” (BRASIL; CEDH, 2013, p. 45), as narrativas contidas nas

\footnotetext{
3- No CEDH (p. 28) há toda uma explanação sobre o modo como as orientações das propostas, formadoras das diretrizes, acerca da EDH estavam em consonância com as orientações dos técnicos das Nações Unidas.

4- "É adequado mencionar que, quando o Brasil se torna signatário de um pacto internacional, este passará a compor a legislação infraconstitucional, portanto, parte do ordenamento interno" (BRASIL; CEDH, 2013, p. 12).
} 
diretrizes sobre "a educação para a mudança e a transformação social" (BRASIL; CEDH, 2013, p. 42) e "o método de aplicação das ações para a educação para os direitos humanos" (BRASIL; CEDH, 2013, p. 43), entre muitas outras questões.

0 respectivo caderno busca comunicar, aos diversos segmentos educacionais, as Diretrizes Nacionais da Educação em Direitos Humanos e seus pareceres e resoluções (2012a; 2012b), bem como as prescrições presentes em outros planos e programas anteriores sobre os direitos humanos. A opção pelo Caderno, como um dos campos de pesquisa, deve-se ao fato de que nele estão sistematizadas discussões mais amplas que vão desde o Programa Nacional de Direitos Humanos I (PNDH, 1996), passando pelo Plano Nacional de Educação em Direitos Humanos (PNEDH, 20035) até o Programa Nacional de Direitos Humanos III (PNDH3, 2010), o qual possuía um eixo voltado para a temática da Educação em Direitos Humanos. 0 CEDH também tem uma parte voltada para a exposição de metodologias de implantação de políticas educacionais e pedagógicas voltadas para os direitos humanos.

0 Caderno tem uma organização mais adequada a uma pesquisa documental de caráter histórico-hermenêutico, pois seus elaboradores fazem, nos dois primeiros capítulos, antes de apresentar os princípios e as propostas metodológicas das Diretrizes Nacionais da Educação em Direitos Humanos, uma contextualização histórica tanto dos direitos humanos quanto da educação associada aos direitos humanos no Brasil e no mundo. Correlaciona ainda as diretrizes a um esforço nacional e internacional de ampliação de uma educação em e para os direitos humanos.

Maria do Rosário Nunes (2013, p. 4), ministra-chefe da Secretaria dos Direitos Humanos, no momento de publicação do CEDH, fazia a seguinte diferenciação entre as Diretrizes Nacionais da Educação em Direitos Humanos e o Caderno de Educação em Direitos Humanos:

As diretrizes têm como fundamento os seguintes princípios: a dignidade humana; a igualdade de direitos; o reconhecimento e a valorização das diferenças e das diversidades; a laicidade do Estado; a democracia na educação; a transversalidade, a vivência e a globalidade; e a sustentabilidade socioambiental. [...] A publicação do Caderno [...] tem o propósito de divulgar e difundir informações relativas à educação em direitos humanos, segundo o que preconiza o Programa Mundial de Direitos Humanos. (2005-2014). (NUNES, 2013, p. 4).

Esclarece-se que a metodologia de análise dos documentos orienta-se por uma perspectiva externalista (MEDINA, 1982), ou seja, a análise não é somente interna (textual) aos documentos, mas também voltada para a compreensão dos contextos sócio-históricos nos quais eles são produzidos. No livro A sociedade dos individuos, Norbert Elias (1994) fornece muitas pistas para ajudar a solucionar as dificuldades que a análise sociológica enfrenta, ao lidar com o desafio de compreender, simultaneamente, os embates entre as muitas configurações, as relações de interdependências e os valores que dão significado a ações, ideias, discursos, argumentos, narrativas, práticas e procedimentos reforçadores

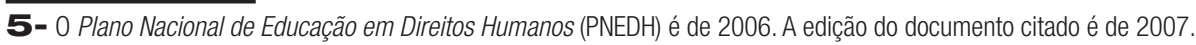


de outros valores. Esta análise não se atém somente à busca, no interior do texto, de uma estrutura argumentativa, porque ela pode conduzir, conforme diz Elias (1999a, p. 143), a "substantivos desumanizados", ou melhor, a certa autonomia do argumento em relação às complexidades configuracionais geradoras dele" (REZENDE, 2015, p. 37). Reconhece-se, porém, que a abordagem textual (interna) tem relevância para esta análise. Combinam-se, então, as vertentes externalistas e internalistas (MEDINA, 1982). "A linguagem ocupa um papel central [uma vez] que não existe conhecimento sociológico que não passe [pela] linguagem, [que é sempre] situada" (MELUCCI, 2005, p. 33). Portanto, "tudo o que é dito, é dito para alguém em algum lugar" (MELUCCI, 2005, p. 33) e em um dado contexto espacial e histórico.

0 objeto deste artigo, portanto, são as correlações, similaridades e correspondências existentes entre as instruções e as orientações contidas nos RDHs e nos REPTs e aquelas contidas no CEDH, direcionadas à geração de "espaços para o desenvolvimento das ações educativas” (BRASIL; CEDH, 2013, p. 53) impulsionadoras de práticas de governança capazes de envolver uma multiplicidade de agentes da comunidade escolar e fora dela. Trata-se de agentes que estejam empenhados na construção e efetivação de procedimentos e de práticas que possam fomentar, no universo escolar, a constituição de seres sociais não só conhecedores de seus direitos, mas também que sejam capazes de expandir, de modo contínuo, as suas ações, motivações e disposições em direção a uma busca contínua da efetivação dos direitos humanos para todos os segmentos sociais.

Os formuladores do Caderno Educação em Direitos Humanos (CEDH) denominam o processo de empoderamento (processo de investir-se a si mesmo de poder, de autonomia, de liberdade para agir e de habilidade e capacidade políticas) como um conjunto de ferramentas que vão sendo construídas de modo a "emancipar os indivíduos para que eles próprios tenham capacidade para defender os interesses da coletividade" a que pertencem (BRASIL; CEDH, 2013, p. 13). Não há dúvida de que as sugestões de governança se chocam com os extremados desequilíbrios de poder existentes no Brasil, os quais criam bloqueios quase que irremovíveis obstando assim a um melhor equilíbrio de poder e à possibilidade de articulação entre diversas forças sociais.

Parte-se do pressuposto de que, em vista de outras análises já realizadas sobre os REPTs e os RDHs, as noções de governança, que emolduram tanto o CEDH quanto esses documentos internacionais, comungam de uma mesma convicção: a de supor que a solução para os diversos problemas nas áreas sociais, educacionais e políticos está na construção de interações entre agentes e agendas diversas a fim de ir, paulatinamente, abrindo espaços para que os vários segmentos sociais possam tornar públicas as suas demandas e interesses. Percebe-se que os RDHs bem como os REPTs tentam situar seus diagnósticos e prescrições no âmbito de uma abordagem de direitos humanos e é por isso que se notam muitas similaridades entre eles e o CEDH.

Esta investigação orienta-se, então, pelos seguintes problemas sociológicos: de que modo é possível encontrar correlações, similaridades e proximidades entre, de um lado, a noção de governança orientadora das prescrições de políticas, que levem ao desenvolvimento humano e ao cumprimento das metas Educação para Todos (EPTs), presentes nos RDHs (PNUD; RDHs, 1990, 2000, 2001, 2004, 2010, 2014) e nos REPTs 
(UNESCO; REPTS, 2002, 2009, 2010, 2012) e, de outro, as linhas de ações, sugeridas pelo Caderno Educação em Direitos Humanos (CEDH)? Por que tais políticas de governança, na área da educação, formariam indivíduos, simultaneamente, sujeitos de direitos e impulsionadores de ações que estimulem práticas suscitadoras dos direitos humanos?

No que tange ao combate à violência e às discriminações, por que os $\mathrm{RDHs}^{6}$, os REPTS $^{7}$ e o CEDH supõem que as políticas e ações levadas a cabo por diversos agentes, ou seja, dentro da modalidade denominada de governança, são as mais efetivas e indicadas para a construção de uma vivência apta à implantação de projetos coletivos que garantam a ampliação de uma educação para e em direitos humanos? No caso de sociedades excludentes e desiguais como a brasileira, o que significam essas apostas de mudanças expressivas através de processos de governança? Em situações de desequilíbrios gritantes de poder e de riqueza, de que forma expandir uma educação em direitos humanos que possibilite empoderar ${ }^{8}$, de fato, "os atores sociais, especialmente os marginalizados ${ }^{9}$ e excluídos”? (BRASIL; CEDH, 2013, p. 43).

\section{Governanças, o que são? Em questão as propostas dos RDHs, dos REPTS e do CEDH}

Ao lerem-se os RDHs e os REPTs constata-se que, na efetivação de políticas de ampliação das melhorias educacionais e de todas as demais, as diversas sugestões de ações e de procedimentos estão, inteiramente, afinadas com algumas perspectivas de governança que têm ganhado terreno no decorrer do século XX e no limiar do XXI. Esclarece-se que existem muitas noções, visões, definições e entendimentos de governança (TORRES, 2016; NICKEL, 2012; RADIN, 2010; SMITH, 2010; MILANI; SOLINIS, 2002; KAZANCIGIL, 2002), que não é um conceito uniforme, mas poliforme e de enorme plasticidade, portanto, adaptável a várias situações e contextos, daí o seu largo emprego na atualidade.

Milani e Solinis (2002) fazem um mapeamento das muitas visões sobre governança. Trata-se de visões que vão conceituar governança ora como gestão cooperativa de Estados e empresas - passando por eficácia, eficiência, privatização e parceria entre a esfera pública e a esfera privada - ora como sistema sociocibernético ${ }^{10}$ organizado em redes múltiplas onde há partes ricas em energia (poder) e partes ricas em informações (cultura). Essas duas partes produzem uma dinâmica capaz de gerar pautas, agendas e mudanças.

Desse ou daquele modo, pode-se dizer que as propostas de governança, sejam elas locais, nacionais ou internacionais, recorrem com frequência à ideia de atores, de agentes, de participação e de redes. Em torno desses elementos giram as mais diversas visões,

6 - 0 RDH de 2004 é, inteiramente, dedicado a essa questão ao demonstrar que o desenvolvimento humano só ocorrerá se houver políticas, comandadas por diversos agentes, na escola e em outras instâncias, que combatam todas as formas de discriminação, preconceitos e violências. 7- 0 REPT de 2009 é todo voltado para a temática da governança e seus efeitos para o cumprimento das metas da Educação para Todos (EPT). 8- Celso Furtado (2002) discutiu os bloqueios - que minam qualquer empoderamento - derivados de alguns parâmetros (concentração de terra, de renda, de recursos, de poder) que estruturam a sociedade brasileira.

9- Note-se que as DNEDHs e os REPTs reciclam o conceito de marginalização. Essa noção, que ficou adormecida por algum tempo, tem aparecido, no limiar do século XXI, em alguns documentos.

10- Talcott Parsons desenvolveu um modelo de explicação do sistema de ações e de seus controles e organização hierárquica. Ele lança mão da ideia de hierarquia cibernética para entender os condicionamentos e (im) possibilidades das ações. Sobre isso ver Rocher (1976). 
noções e definições de governança. Pode-se perguntar o seguinte: o que os RDHs e os REPTs entendem por governança ${ }^{11}$ ? Como a caracterizam ${ }^{12}$ ?

A ideia de governança empresarial, nascida na década de 1930 com o intuito de criar formas de gestão e gerenciamento que facultassem aos dirigentes empresariais compartilhar responsabilidades, na ampliação da produtividade e na administração dos conflitos, foi-se metamorfoseando ao longo do século XX. Tal ideia ganhou corpo vindo a incorporar, em sua formulação, diversas dimensões que foram adentrando as prescrições de ações no âmbito público e privado e se relacionando tanto às formas colegiadas de lidar com os desafios advindos dos padrões de autoridades e lideranças quanto aos modos de gerir recursos, parcerias e formas de ampliação de capacidades gerenciais e comunicativas, nos planos horizontais e verticais no interior dos ambientes empresariais (RADIN, 2010), estatais, governamentais e intergovernamentais ${ }^{13}$.

A noção de governança, aplicada, em um primeiro momento, a processos de gestação empresarial, vai se ampliando e enlaçando diversos segmentos, desde os estatais e intergovernamentais até as organizações da sociedade civil. Os chamados processos de governança passam, desde as últimas décadas do século XX, a ser defendidos como os únicos com envergadura para, nos planos local, nacional e internacional, responder aos desafios de articular as muitas demandas e os muitos agentes (governamentais e nãogovernamentais, estatais e não-estatais). Eli Diniz (2013) considera que os processos de governança são "formas de gestão caracterizadas pela capacidade de construir instâncias de interlocução com a sociedade, voltadas para defınir as prioridades da agenda pública, abrindo espaço para a consecução das metas coletivas e a sustentação política das decisões tomadas" (DINIZ, 2013, p. 17).

Por essa razão, quando encampam a ideia de que a governança é o modo mais plausível de administrar recursos, agendas, políticas, demandas, comportamentos, gestão e, até mesmo, expectativas e perspectivas de viabilizar ações e procedimentos, os organismos internacionais (como o PNUD, por meio dos RDHs, e a UNESCO, por meio dos REPTs) estão assinalando que os desafios do presente, referentes às políticas de ampliação das metas da Educação para Todos e do desenvolvimento humano nos seus três eixos básicos (educação, saúde, renda) exigem articulações complexas de vários agentes e níveis locais, nacionais e globais.

Atingir as metas da Educação para Todos e do desenvolvimento humano sustentável aparece nos REPTs e nos RDHs como uma operação complexa que tem de enlaçar uma

\footnotetext{
11- Ressalte-se que a discussão sobre governança tem estado presente, de maneira acentuada, no debate acadêmico. Não é algo que está circunscrito aos órgãos do Estado, aos organismos internacionais e às organizações da sociedade civil no que tange ao encaminhamento de ações e procedimentos. Ver sobre isto Dubrow (2013).

12- Deve-se atentar para o fato de que os RDHs são produzidos em inglês e quando são traduzidos para o português e/ou para 0 espanhol parece darem margem à dúvida sobre como traduzir o termo governance, o qual foi traduzido para governação ou gobernación. No decorrer da década de 1990 e da de 2000, não se fizeram distinções precisas sobre as noções de governança e governação. 0 RDH de 2010 procurou demarcar, ainda que de modo incipiente, as diferenças entre esses dois termos.

13 - As políticas intergovernamentais são aquelas que operam em associações diversas em múltiplos níveis envolvendo Estados, organizações da sociedade civil e organismos internacionais e organizações intergovernamentais, tais como: OMS (Organização Mundial de Saúde), OMC (Organização Mundial do Comércio), OIT (Organização Internacional do Trabalho); ONU (Organização das Nações Unidas) e inúmeras outras.
} 
multiplicidade de agentes ${ }^{14}$. De acordo com Milani e Solinis (2002), a ampliação de demandas e de atores combinada com a questão acerca de como obter recursos para implantar tais políticas tem levado a uma ampliação da ideia de governança que se assenta, essencialmente, numa convicção, plausível ou não, de que é necessário tecer redes e mais redes de atores com capacidade de construir demandas, gerir e implementar políticas que levem a um desenvolvimento social e humano ${ }^{15}$ duradouro, o qual pode ser entendido como:

[...] o alargamento das liberdades e capacidades que as pessoas possuem para viverem vidas que valorizam e que têm motivos para valorizar. As liberdades e capacidades que nos permitem viver vidas com significado vão além da satisfação das necessidades básicas. (PNUD; RDH, 2011, p. 19-20).

Tecer essas redes pressupõe a possibilidade de ir construindo novos equilíbrios de poder, o que é, conforme diz Norbert Elias (1999b; 2006), uma das tarefas mais difíceis que a humanidade tem enfrentado ao longo de sua história. Fazer com que ocorra uma, embora pequena, desconcentração do poder "a favor daqueles [estratos] que" (ELIAS, 1999b, p. 68) não têm qualquer força política é um desafio incomensurável. Há no interior dos RDHs, dos REPTs e das DNEDHs uma narrativa que tenta impulsionar uma crença sólida nessa possibilidade. E isso é feito através da ideia de governança.

Os elaboradores do RDH de 2009 ressaltam que, no limiar do século XXI, houve muitas tentativas de colocar em prática políticas de governança, mas elas não foram eficazes, porque ocorreram dificuldades que obstaram à efetividade de tais políticas no combate às desigualdades. Deve-se indagar se estas últimas podem ser revertidas, ainda que parcialmente, por meio de políticas de governança. Desigualdades derivadas dos parâmetros estruturais de uma sociedade, tais como concentração de renda, propriedade, recursos e poder, só podem ser diminuídas com alterações estruturais que mudem tais parâmetros, conforme adverte Celso Furtado (2002).

A governança como uma forma associativa e democrática de atuação de diversos agentes, incluindo-se os mais pobres, pressuporia processos de distribuição de poder que não têm estado no horizonte de qualquer nação no mundo atual; ainda assim, os RDHs e os REPTs insistem que ela é possível e realizável se os governantes tiverem a capacidade de utilizar, eficientemente, os recursos arrecadados (PNUD; RDH, 2013, p. 209) para que os mais pobres sejam, paulatinamente, incluídos social e politicamente. 0 CEDH parece estar de acordo com essa ideia, já que desejam propor práticas educacionais que impulsionem os mais pobres a exigirem os seus direitos. O Caderno Educação em Direitos Humanos pode ser tomado como exemplo disso quando pressupõe, no item sobre gestão democrática, que os processos de administração devem refletir no seu cotidiano práticas democráticas

14- No caso dos REPTs, que tratam da questão da governança na educação, fica evidenciada essa tentativa de indicar quais são os atores, os agentes e as redes capazes de operar mudanças no sistema educacional pelo mundo afora. E fica ora implícita ora explícita a sugestão de que entre esses agentes estão os setores privados que teriam também um papel relevante nesse processo. Nota-se que os formuladores dos documentos estão pensando nas escolas, institutos e fundações ligadas aos setores empresariais e que possuem projetos voltados para os segmentos populares.

15- A abordagem do desenvolvimento humano presente nos RDHs tem muito em comum com as formulações teóricas de Amartya Sen (1981, 2008, 2010), o qual, junto com Mahbub UI Haq $(1978,1995)$, foi um dos idealizadores dos RDHs. 
de integração "da comunidade escolar com a comunidade do entorno escolar" (BRASIL; CEDH, 2013, p. 53).

0 RDH de 2002 foi construído inteiramente com o objetivo de prescrever a aplicação da noção de governança aos processos de desenvolvimento humano assentado em ações e procedimentos democráticos. 0 objetivo essencial era atestar que a governança somente seria possível se as populações mais pobres fossem obtendo alguma forma de poder político. Caso as pessoas não se invistam de poder, de autonomia, de habilidade e de capacidade política não há desenvolvimento humano nem segurança humana. A governança é tomada pelos produtores do RDH de 2002 como resultado do contínuo aperfeiçoamento da democracia. A governança não é tomada como forma tecnocrática de exercício de poder, nem como forma de gestão entre pares, mas sim como resultado de novos equilíbrios de poder. Daí a ideia recorrente de ampliação da participação popular para que os mais pobres tenham canais de participação política.

0 REPT de 2009 dedica-se inteiramente à governança. Uma das questões problematizadas nesse documento é o fato de que a tentativa de aplicar a noção de governança em contextos concretos tem sido desafiada pelas dificuldades de enfrentar, nas ações e procedimentos, além do problema da participação, o da equidade. Por isso, a preocupação com as desigualdades ocupa o lugar central nas propostas de governança para a área de educação e de políticas educacionais. Os formuladores desse documento fazem diagnósticos e prescrições em busca de caminhos por onde os países devem trilhar para encontrar formas de combater as desigualdades sociais e educacionais e as desvantagens extremas vivenciadas pelos mais pobres em contraposição aos mais abastados. Segundo eles, toda e qualquer política educacional mais inclusiva exigia "liderança governamental comprometida e eficaz, assim como um setor público que disponha de recursos humanos e financeiros para superar as desvantagens. Mais do que isso, é preciso boa governança” (UNESCO; REPT, 2009, p. 6).

Nota-se que há nos REPTs preocupação em distinguir formas adequadas e inadequadas de governança no que diz respeito à possibilidade de estar voltada para o combate às desigualdades, pobreza e desvantagens socioeducacionais de alguns grupos sociais.

\section{- Caderno Educação em Direitos Humanos e a gestão democrática por meio de práticas e de procedimentos de governança}

Não há dúvida de que o Caderno Educação em Direitos Humanos, ao aventar diversas prescrições e recomendações para trabalhar a educação em direitos humanos na educação básica, está buscando criar práticas e procedimentos convergentes em torno desses objetivos. Transparece quão inexequíveis são, se tomados ao pé da letra, muitos dos objetivos dos elaboradores do CEDH, os quais se empenham em construir uma narrativa inconteste sobre a necessidade de os diversos agentes, tanto os escolares quanto os que circundam a vida escolar, irem desenvolvendo ações que gerem convergência de práticas em prol dos direitos humanos traduzidos em uma vida cada vez menos privada de habilidades e de capacidades profissionais e políticas e cada vez mais voltada para o combate a preconceitos, discriminações e violências de diversas naturezas. A falta de 
nutrição, moradia, saneamento, escola e conteúdos escolares adequados são formas de violência. São formas de violência também todas as privações e impotências que afligem parte expressiva das pessoas mais pobres.

Consta, no capítulo quatro do Caderno Educação em Direitos Humanos (CEDH), o quão complexo seria esse processo de implantação de políticas que levem a uma formação escolar capaz de ampliar as expectativas de inclusão social e política. A EDH estaria sendo desafiada pelas condições de privação e impotência já instauradas e, ao mesmo tempo, estaria também desafiando tais condições. Entra aí a proposta de governança como a única capaz de gerar resultados sustentáveis a curto, médio e longo prazo, já que uma multiplicidade de agentes teria seus procedimentos convergentes em torno dos propósitos da EDH, responsável, por sua vez, por:

[...] estimular ações que contribuam para a transformação da sociedade, tornando-a mais humana, socialmente mais justa e, também, voltada para a preservação da natureza. Como processo educativo, a EDH é um chamamento à responsabilidade. (BRASIL; CEDH, 2013, p. 50).

A ideia de chamamento à responsabilidade está na base da ideia de governança empregada no documento e tem, por certo, a necessidade de refutar uma noção de governança tecnocrática que nada tem a ver com gestão democrática, participação ampliada e preocupação com justiça social. Toda ideia de que a educação tem de "afirmar valores e estimular ações" (BRASIL; CEDH, 2013, p. 50) que melhorem a vida social em seu conjunto, porque procura desmontar, paulatinamente, todas as formas de violência, serve, no caso do Caderno Educação em Direitos Humanos, para tentar enlaçar uma multiplicidade de agentes em um processo de governança destinada a alimentar ações e procedimentos que façam os estudantes saberem que o "conhecimento sobre os direitos humanos se arquiteta na medida em que os homens tomam consciência das diferentes verdades sobre liberdade, justiça, igualdade, dignidade humana" (BRASIL; CEDH, 2013, p. 50).

Os formuladores do CEDH constroem uma narrativa que vai traçando um caminho por onde seja possível visualizar, no horizonte, a possibilidade de os indivíduos irem se investindo de poder, de autonomia e de liberdade para um agir político gerador de melhorias sociais para todos. Eles fazem isso tendo como ponto de partida a defesa de uma educação que expresse na prática o cumprimento dos direitos fundamentais possuídos por todos em relação ao acesso à educação. A condição cidadã como uma construção social é, realmente, algo viabilizada pelo processo educacional. De certa forma, percebe-se no CEDH aquilo que se encontra presente nas discussões de Bauman (2001, p. 41) acerca da passagem da autonomia de jure para a autonomia de facto. Esta última seria alcançada, segundo as diretrizes, por meio de uma formação escolar que contemplasse conteúdos, metodologias, práticas e procedimentos embasados numa perspectiva de direitos.

Conquanto a proposta de Bauman seja diferente em vários aspectos, já que ele não está pensando especificamente no papel da educação na construção da passagem da condição de jure para a condição de facto, há algo similar, ou seja, o longo processo de formação da condição cidadã que só é desencadeada pela geração das condições para criar habilidade e capacidade políticas ancoradas na "construção de uma responsabilidade 
coletiva" (BRASIL; CEDH, 2013, p. 38). Para os preparadores do CEDH, a educação, a escola, o cotidiano escolar e suas práticas teriam de auxiliar nisso sem sombras de dúvidas.

A base para esse plano de ação fundamenta-se na perspectiva da associação entre [...] governos, [e entre] governos [...] [e] organizações não governamentais e vários outros setores da sociedade civil, objetivando a formação de cidadãos e cidadãs capazes de conhecer, defender e promover os direitos humanos. (BRASIL; CEDH, 2013, p. 30).

A ideia de governança democrática, presente no documento em análise, como aquela derivada da associação entre vários agentes aventa também a possibilidade, já discutida no final do século XIX e início do século $\mathrm{XX}^{16}$, de que se gere, no país, uma educação republicana, fruto tanto de um modo de conceber os conteúdos e metodologias (que abarcassem os direitos, a justiça e a vida social como um todo) quanto de uma maneira de agir no ambiente escolar.

Por valores republicanos entendem-se: (a) 0 respeito às leis, legitimadas pela aprovação soberana do povo e acima das vontades particulares; (b) 0 respeito ao bem público, acima do interesse privado; e (c) 0 sentido da responsabilidade no exercício do poder, inclusive o poder implícito na ação dos educadores, sejam professores, sejam gestores do ensino. [...] Por valores democráticos entendem-se: (a) 0 amor à igualdade e consequente horror aos privilégios; (b) A aceitação da vontade da maioria legitimamente formada, decorrente de eleições ou de outro processo democrático, porém com constante respeito aos direitos das minorias; e (c) Em consequência dos tópicos acima, configura-se como conclusivo o respeito integral aos Direitos Humanos [...]. (BRASIL; CEDH, 2013, p. 38).

Não há dúvida de que o desejo de geração de uma educação republicana favorecedora da internalização, por todos, de uma perspectiva de direitos, é um desafio incomensurável no país. E o foi ao longo da história. Por isso, conforme foi dito anteriormente, as ambições do CEDH são altíssimas e vão desde a instituição de uma educação republicana capaz de impulsionar a condição cidadã até a instauração de um processo no qual as pessoas vão, paulatinamente, investindo-se de poder, de autonomia e de liberdades para lutar contra a privação (nas suas muitas facetas) e a impotência política no geral. Trata-se do processo entendido como norteado por práticas de governança.

Educar para os direitos humanos implica em tomar a decisão e assumir o compromisso de exercer a cidadania de maneira irrestrita, voluntária e cooperativa. Essa ação requer a constituição de alianças entre os membros da sociedade civil, formando redes, e entre o estado e a sociedade civil, o que fortalece a luta na defesa dos direitos humanos. (BRASIL; CEDH, 2013, p. 40).

16- Sílvio Romero e Manoel Bomfim discutiram fartamente, no limiar do século XX, a necessidade e os desafios de instituir, no país, uma educação republicana. 
Destaque-se que os formuladores do CEDH procuram dizer que são dois os paradigmas orientadores de suas propostas: a defesa da dignidade humana (em todos os seus aspectos) e da interculturalidade. A defesa desta última seria uma forma de desmontar os preconceitos, as violências e as discriminações. A EDH estaria orientada por esses dois pilares que se reforçam mutuamente através das práticas de governança na gestão democrática da escola, do cotidiano escolar e dos projetos políticos pedagógicos.

Nessa perspectiva, a sociedade civil, os movimentos sociais e as instituições formais de construção do saber constroem suas articulações e intercâmbios, constituindo redes de ações solidárias e emancipatórias. (BRASIL; CEDH, 2013, p. 40).

Note-se que a governança é entendida como um processo de "convergência das forças sociais” (BRASIL; CEDH, 2013, p. 40) pelo desmonte, a longo prazo, das discriminações e violências que atingem um grupo enorme de pessoas (os pobres, as mulheres, os negros, os indigenas, os migrantes, os homossexuais). Todos os indivíduos nessa condição teriam de dotar-se, pouco a pouco, de poder e de autonomia para lutar pelos direitos de não sofrer qualquer tipo de violência e de restrição a sua liberdade e autonomia.

No universo escolar, como ocorreria esse investir-se de poder? De um lado, através de um tipo de gestão do ambiente e do cotidiano escolar em que as pessoas se sintam parte de um processo decisório, de outro, pelo modo como os conteúdos escolares seriam passados aos alunos através de uma metodologia (modelo de levantamento de problemas) que contemplasse o desenvolvimento de habilidades e capacidades para fazer diagnósticos e prescrever soluções. Os estudantes seriam, então, treinados tanto a lidar com as situações problemáticas, em vez de fugir delas, quanto a procurar soluções para os conflitos, as discriminações, os preconceitos e as violências.

A EDH seria uma ferramenta para constituição de sujeitos ativos, capacitados e dispostos a empenhar esforços em favor da comunidade como um todo. "A Educação em Direitos Humanos deve ser orientada para a comunidade. Deve sensibilizar o indivíduo a participar de um processo ativo na resolução dos problemas em um contexto de realidades específicas [...]" (BRASIL; CEDH, 2013, p. 40). Esse tipo de educação deixaria sempre evidenciado que as soluções são de natureza individual e coletiva simultaneamente.

Deve-se considerar que muito antes dos investimentos do Estado brasileiro direcionados à implantação de diretrizes e de políticas garantidoras de uma educação em e para os direitos humanos, alguns acadêmicos da área educacional já vinham labutando para isso há algumas décadas. Maria Victória Benevides (2000) merece destaque entre eles. Em seu livro Educação em Direitos Humanos: de que se trata? ela esclarece o quão importante era envidar esforços nessa direção.

0 que significa dizer que queremos trabalhar com Educação em Direitos Humanos? A Educação em Direitos Humanos é essencialmente a formação de uma cultura de respeito à dignidade humana através da promoção e da vivência dos valores da liberdade, da justiça, da igualdade, da solidariedade, da cooperação, da tolerância e da paz. Portanto, a formação desta cultura significa criar, influenciar, compartilhar e consolidar mentalidades, costumes, atitudes, hábitos 
e comportamentos que decorrem, todos, daqueles valores essenciais citados - os quais devem se transformar em práticas. (BENEVIDES, 2000, p. 1).

\section{Considerações finais}

Os formuladores do CEDH deixam claro seu entendimento de que há problemas relacionados à pobreza, à miserabilidade, às desigualdades, à privação que não têm como ser resolvidos a curto prazo. A solução passa a ser, então, o "envolvimento e compromisso das pessoas [...] [empenhadas] na luta pela defesa e proteção dos direitos humanos, que tornarão possível a continuidade das ações com novos atores e instituições" (BRASIL; CEDH, 2013, p. 40). Seria isso suficiente para gerar novos equilíbrios de poder numa sociedade extremamente desigual como a brasileira? 0 documento não responde e não o faz pela sua própria natureza, uma vez que seu objetivo é instigar as diversas forças sociais e instituições a criar condições para que se possa efetivar "a consolidação da EDH como uma política pública” (BRASIL; CEDH, 2013, p. 40).

Nos mesmos moldes dos RDHs e dos REPTs, o CEDH procura indicar a seguinte orientação: embora não esteja no horizonte a efetivação de mudanças nos parâmetros estruturais (concentração de renda, de poder, de propriedade, de recursos) da sociedade brasileira, é necessário criar e incentivar "programas e projetos educativos com vistas a promoção e defesa dos direitos" (BRASIL; CEDH, 2013, p. 40). Os elaboradores do Caderno tentam convencer a todos os segmentos envolvidos com a educação de que é necessário estabelecer um tipo de orientação acerca das práticas educacionais que aponte para um contínuo incentivo a fim de que todos (alunos, professores, gestores escolares, organizações da sociedade civil, entre outros) se empenhem na defesa dos direitos humanos.

Tal processo, a médio e longo prazo, poderia fazer surgir sujeitos sociais habilitados e capacitados politicamente para travar uma luta persistente pela dignidade humana. Esse tipo de aposta contém muitos desafios. Todavia, em uma situação social de retrocessos nas conquistas dos direitos sociais, ampliação das desigualdades (de poder, de renda, de patrimônio) e inocuidade de inúmeras lutas e reivindicações sociais, empenhar-se em manter expectativas e perspectivas de melhorias sociais que garantam e reiterem ações em prol do desenvolvimento humano, da segurança humana e dos direitos humanos é uma forma de enfrentar os inúmeros desafios que vão surgindo no limiar do século XXI. De um lado, as metas de ampliação da dignidade humana ganham notoriedade, de outro, veem-se alargadas as zonas de inseguridade e de subtração de direitos.

No decorrer dos anos vindouros, deve-se, segundo os produtores dos documentos analisados, ir formando, a duras penas, experiências subjetivas que indiquem caminhos e possibilidades de lutar pelos direitos e pela dignidade humana. Teria, então, papel primordial a expansão de modos democráticos de governança em que indivíduos e coletividade fossem construindo novos rearranjos e novas correlações de força. A EDH seria uma forma de fazer com que as pessoas possam ir se "rebelando contra classificações sociais que os aprisionem" (SOARES, 2016, p. 6). Tal processo diz respeito às pessoas e às coletividades ao mesmo tempo.

Ao lerem-se o $\mathrm{CEDH}$, têm-se as mesmas impressões causadas pelas leituras dos RDHs e dos REPTs: são prescrições que indicam, em primeiro lugar, a necessidade de 
mudar as subjetividades dos excluídos e marginalizados. No entanto, para que isso ocorra, muitas outras pessoas, em melhores condições, teriam de estar envolvidas em projetos e na política; daí, a proposta de governança democrática, que, posta em prática, leve os indivíduos que vivenciam situações de amplíssimo sofrimento social ${ }^{17}$ a acreditar que existem mudanças possíveis, não obstante serem muito complexas e difíceis. 0 dado interessante é que nesses três documentos se percebe que há empenho em situar seus diagnósticos e prescrições no âmbito de uma abordagem dos direitos humanos e sociais, o que é uma forma de rechaçar as perspectivas que supostamente defendem que os próprios pobres devem encontrar, individualmente, soluções para seus problemas (ETCHICHURY, 2015). As soluções indicadas pelas ações assinaladas no CEDH são coletivas, se bem que passem por mudanças individuais. "Os direitos humanos ganham [desta forma] seu lugar prioritário, assim como a dignidade da pessoa” (SOARES, 2016, p. 6).

\section{Referências}

BAUMAN, Zygmunt. Globalização: as consequências humanas. Rio de Janeiro: Jorge Zahar, 1999.

BAUMAN, Zygmunt. Modernidade líquida. Rio de Janeiro: Jorge Zahar, 2001.

BENEVIDES, Maria Victória. Educação em direitos humanos: de que se trata? Programa ética e cidadania construindo valores na escola e na sociedade. Brasília, DF: Ministério da Educação e Cultura, 2000. Disponível em: http://www.dhnet.org.br/dados/boletins/edh/br/boletim1.html. Acesso em: 09 set. 2020.

BOURDIEU, Pierre (org.) A miséria do mundo. Petrópolis: Vozes, 2003.

BRASIL; PNDH I. I Programa Nacional de Direitos Humanos. Decreto n.1.904/1996. Brasília, DF: Secretaria de Direitos Humanos, 1996. Disponível em: http://www.planalto.gov.br/ccivil_03/decreto/ D1904.htm. Acesso em: 09 set 2020.

BRASIL; PNDH 3. III Programa Nacional de Direitos Humanos. Brasília, DF: Secretaria de Direitos Humanos, 2009. Disponível em: http://www.planalto.gov.br/ccivil_03/_ato2007-2010/2009/decreto/ d7037.htm. Acesso em: 09 set. 2020.

BRASIL. Parecer CNE/CP n 8/2012 - Diretrizes para a Educação em Direitos Humanos. 2012. Brasília, DF: Ministério da Educação e Cultura, 2012. Disponível em: http://portal.mec.gov.br/escola-de-gestores-daeducacao-basica/323-secretarias-112877938/orgaos-vinculados-82187207/17631-2012-pareceresdo-conselho-pleno. Acesso em: 10 set. 2020.

BRASIL. Plano Nacional de Educação em Direitos Humanos (PNEDH). Comitê Nacional de Educação em Direitos Humanos. Brasília, DF: Secretaria Especial dos Direitos Humanos: Ministério da Educação, 2003. Disponível em: http://new.netica.org.br/prevencao/cartilha/plano-educdh.pdf. Acesso em: 09 set. 2020.

17- Essa noção de sofrimento social foi trabalhada por Bauman (1999) e Bourdieu (2003). 
BRASIL. Resolução n. 1 de 30 maio de 2012. Estabelece Diretrizes Nacionais para a Educação em Direitos Humanos. Disponível em: http://portal.mec.gov.br/dmdocuments/rcp00112.pdf. Acesso em: 20 maio 2019.

BRASIL; CEDH - Caderno de Educação em Direitos Humanos: diretrizes nacionais. Brasília, DF: Coordenação Geral de Educação em SDH/PR; Direitos Humanos; Secretaria Nacional de Promoção e Defesa dos Direitos Humanos, 2013.

CÂNDIDO, Antônio. Para pensar o problema da fome. Folha de S. Paulo, São Paulo, C 6, p. 6, 29 nov.1999.

DINIZ, Eli. Desenvolvimento e estado desenvolvimentista: tensões e desafios da construção de um novo modelo para o Brasil do século XXI. Revista de Sociologia Política, Curitiba, v. 21, n. 47, p. 9-20, 2013.

DURBOW, Joshua K. Governança global democrática, desigualdade política e a hipótese da resistência nacionalista. Sociologias, Porto Alegre, n. 32, p. 94-110, 2013.

ELIAS, Norbert. A sociedade dos indivíduos. Rio de Janeiro: Jorge Zahar, 1994.

ELIAS, Norbert. Conceitos sociológicos fundamentais: civilização, figuração, processos sociais. In: NEIBURG, Federico; WAISBORT, Leopoldo Garcia (org.). Escritos \& ensaios. Rio de Janeiro: Jorge Zahar, 2006. p. 21-33.

ELIAS, Norbert. Introdução à sociologia. Lisboa: Edições 70, 1999a.

ELIAS, Norbert. 0 sociólogo como destruidor de mitos. In: ELIAS, Norbert. Introdução à sociologia. Lisboa: Edições 70, 1999b. p. 53-76.

ETCHICHURY, Horacio J. La mente, la pobreza y el banco mundial. Revista Enfoques, Rio de Janeiro, v. 16, n. 23, p. 49-65, 2015.

FURTAD0, Celso. Em busca de novo modelo. Rio de Janeiro: Paz e Terra, 2002.

KAZANCIGIL, Ali. A regulação social e a governança democrática da mundialização. In: MILANI, Carlos; ARTURI, Carlos; SOLINIS, Germán (org.). Democracia e governança mundial: que regulações para 0 século XXI? Porto Alegre: UFRGS; Unesco, 2002. p. 47-62.

MEDINA, Estebán. La polémica internalismo/externalismo en la historia y la sociología de la ciencia. Reis, Madrid, v. 23, n. 83, p. 53-75, 1982.

MELUCCI, Alberto. Por uma sociologia reflexiva. Petrópolis, Vozes, 2005.

MILANI, Carlos; SOLINÍS, Germán. Pensar a democracia na governança mundial: algumas pistas para 0 futuro. In: MILANI, Carlos; ARTURI, Carlos; SOLINIS, Germán (org.). Democracia e governança mundial: que regulações para o século XXI? Porto Alegre: UFRGS; Unesco, 2002. p. 266-291.

NICKEL, Patricia M. Public sociology and civil society: governance, politics, and power. Boulder: Paradigm, 2012. 
NUNES, Maria do Rosário. Apresentação do CEDH. Caderno de Educação em Direitos Humanos (CEDH), Brasília, DF, p. 4-5, 2013.

PNUD; RDH. Informe del desarrollo humano: definición y medición del desarrollo humano. Bogotá: Tercer Mundo, 1990. Disponível em: http://desarrollohumano.org.gt/wp-content/uploads/2016/04/HDR-1990. pdf. Acesso em: 09 set. 2020.

PNUD; RDH. Relatório de Desenvolvimento Humano: a liberdade cultural no mundo diverso hoje. Lisboa: Mensagem, 2004. Disponível em: https://www.br.undp.org/content/brazil/pt/home/library/idh/relatoriosde-desenvolvimento-humano/relatorio-do-desenvolvimento-humano-20004/. Acesso em: 10 set. 2020.

PNUD; RDH. Relatório de Desenvolvimento Humano: aprofundar a democracia num mundo fragmentado. New York: Oxford University Press, 2002. Disponível em: https://www.br.undp.org/content/brazil/pt/home/ library/idh/relatorios-de-desenvolvimento-humano/relatorio-do-desenvolvimento-humano-20002/. Acesso em: 10 set. 2020.

PNUD; RDH. Relatório de Desenvolvimento Humano: a verdadeira riqueza das nações - caminhos para 0 desenvolvimento humano. Washington, D.C.: Communications Development Incorporated, 2010. Disponível em: https://www.br.undp.org/content/brazil/pt/home/library/idh/relatorios-de-desenvolvimentohumano/relatorio-do-desenvolvimento-humano-200010/. Acesso em: 11 set. 2020.

PNUD; RDH. Relatório do Desenvolvimento Humano: direitos humanos e desenvolvimento humano. New York: Oxford University Press, 2000. Disponível em: https://www.br.undp.org/content//brazil/pt/home/ library/idh/relatorios-de-desenvolvimento-humano/relatorio-do-desenvolvimento-humano-2000/. Acesso em: 10 set. 2020.

PNUD; RDH. Relatório de Desenvolvimento Humano: fazendo as novas tecnologias trabalhar para 0 desenvolvimento humano. New York: Oxford University Press, 2001. Disponível em: https://www.br.undp.org/ content/brazil/pt/home/library/idh/relatorios-de-desenvolvimento-humano/relatorio-do-desenvolvimentohumano-20001/. Acesso em: 10 set. 2020.

PNUD; RDH. Relatório de Desenvolvimento Humano: sustentabilidade e equidade: um futuro melhor para todos. Washington, D.C.: Communications Development Incorporated, 2011. Disponível em: https:// www.br.undp.org/content/brazil/pt/home/library/idh/relatorios-de-desenvolvimento-humano/relatorio-dodesenvolvimento-humano-200011.html. Acesso em: 11 set. 2020.

PNUD; RDH. Relatório de Desenvolvimento Humano: sustentar o progresso humano, reduzir as vulnerabilidades e reforçar a resiliência. Washington, D.C.: Communications Development Incorporated, 2014. Disponível: https://www.br.undp.org/content/brazil/pt/home/library/idh/ relatorios-de-desenvolvimento-humano/relatorio-do-desenvolvimento-humano-200013/. Acesso em: 11 set 2020 .

RADIN, Beryl. Os instrumentos da gestão intergovernamental. In: PETERS, Guy; PIERRE, Jon (org.). Administração pública. São Paulo: Unesp, 2010. p. 597-635 
REZENDE, Maria J. de. Uma abordagem histórico-hermenêutica dos relatórios do desenvolvimento humano das Nações Unidas. E-I@tina, Buenos Aires, v. 13, n. 51, p. 32-51, 2015.

ROCHER, Guy. Talcott Parsons e a sociologia americana. Rio de Janeiro: Francisco Alves, 1976.

SEN, Amartya. Desenvolvimento como liberdade. São Paulo: Cia das Letras, 2010.

SEN, Amartya. Desigualdade reexaminada. Rio de Janeiro: Record, 2008.

SEN, Amartya. Poverty and famine: on essai on entitlement and deprivation. Oxford: Oxforf University Press, 1981.

SMITH, Andy. Governança de múltiplos níveis: o que é e como pode ser estudada. In: GUY, Peters; JON, Pierre (org.). Administração pública. São Paulo: Unesp, 2010, p. 619-635.

SOARES, Luiz Eduardo. Em busca de alternativa. Folha de S. Paulo, São Paulo, Cad. Ilustríssima, p. 6, 27 nov. 2016.

TORRES, Roberto Dutra. Governabilidade, governança e poder informal: um problema central de sociologia política. Civitas, Porto Alegre, v. 16, n. 1, p. 153-171, 2016.

UL HAQ, Mahbub. A cortina da pobreza: opções para o terceiro mundo. São Paulo: Nacional, 1978.

UL HAQ, Mahbub. Reflections on human development. New York: Oxford University Press, 1995.

UNESCO; REPTS. Alcançando os marginalizados: relatório de monitoramento global de EPT. Paris: United Nations Educational, Scientific and Cultural Organization, 2010. Disponível em: https://unesdoc.unesco. org/ark:/48223/pf0000186606?posInSet=35\&queryld=N-03d2463f-6e9d-41ea-9119-8e3540be4bd3. Acesso em: 10 set. 2020.

UNESCO; REPTS. Juventude e habilidades: colocando a educação para funcionar: Relatório de monitoramento global de EPT. Paris: United Nations Educational, Scientific and Cultural Organization, 2012. Disponível em: https://unesdoc.unesco.org/ark:/48223/pf0000218003?poslnSet=30\&queryld=N03d2463f-6e9d-41ea-9119-8e3540be4bd3. Acesso em: 11 set. 2020.

UNESCO; REPTS. La Educación Para Todos ¿Va el mundo por el buen camino? Relatório de monitoramento global de EPT. Paris: United Nations Educational, Scientific and Cultural Organization, 2002. Disponível em: https://unesdoc.unesco.org/ark:/48223/pf0000129777?posinSet=49\&queryld=Ne22d0ce3-2eda-4dde-aeb8-f8d4474a73a0. Acesso em: 11 set. 2020.

UNESCO; REPTS. Superando desigualdades: porque a governança é importante: relatório de monitoramento global de EPT. Paris: United Nations Educational, Scientific and Cultural Organization, 2009. Disponível em: https://unesdoc.unesco.org/ark:/48223/pf0000177683?posinSet=37\&queryld=N3bc5bc97-b81f-4dee-8ccd-cf59d168a7fa. Acesso em: 10 set. 2020. 
Recebido em: 11.01.2019

Revisado em: 27.05.2019

Aprovado em: 20.08.2019

Maria José de Rezende é doutora em sociologia pela Universidade de São Paulo. Professora de sociologia no Centro de Letras e Ciências Humanas da Universidade Estadual de Londrina (UEL). Membro dos Programas de Mestrado e Doutorado em Sociologia da UEL. 